\title{
MICROPOLÍTICAS, CURRÍCULOS E FORMAÇÕES NAS INVENÇÕES DAS ESCOLAS
}

\author{
Danielle Piontkovsky ${ }^{(*)}$ \\ Maria Regina Lopes Gomes
}

[...] Democratizar a própria democracia, já que a atual se deixou sequestrar por poderes antidemocráticos.

(SANTOS, 2016, p. 180).

[...] O perfil epistemológico das relações sociais não é fornecido por uma forma epistemológica específica, nomeadamente a forma epistemológica do espaço mundial (a ciência), mas sim pelas diversas constelações de conhecimentos que as pessoas e os grupos produzeme utilizam em campos sociais concretos

(SANTOS, 2000, p.326).

Assumindo com Boaventura de Sousa Santos uma luta política emancipatória possível de provocar mudanças nas relações tecidas nos tempos atuais, afirmamos o caráter epistemológico de todas as formas de conhecimentos. Nesse sentido, desafiadas a compor este artigo para o Dossiê "Educação, democracia e micropolítica", que intenciona afirmar outros modos de existência nesses “tempos sombrios em que estamos vivendo", como professoras e pedagogas da Educação Básica e Superior, desejamos que este seja mais um espaço de luta por desinvisibilizar os processos inventivos que têm afirmado os cotidianos das escolas, das universidades, das ruas, dos movimentos acadêmicos, das mídias, dentre tantos outros como espaçostempos ${ }^{1}$ de (re)existências, produto de um conjunto de relações que apontam as múltiplas singularidades e dimensões da vida na/da educação.

Com Azevedo (2001, p. 18) passamos a compreender que nos cotidianos,

[...] tudo acontece ao mesmo tempo; as boas intenções, muitas vezes, se desmascaram frente às ações ou perdem o ímpeto face aos imprevistos, que não são poucos. Há os usos e as táticas dos praticantes (CERTEAU, 1996), que, não poucas vezes, se contrapõem ao que os 'grandes' discursos ou as políticas oficiais deles esperam.

\footnotetext{
(*) Coordenadora geral de Ensino e professora do Curso de Mestrado em Educação Profissional e Tecnológica (ProfEPT). Membro dos Grupos de Pesquisa do CNPq "Currículos-formação em redes, cotidianos de escolas e direitos humanos" e "Currículos, cotidianos, culturas e redes de conhecimentos". E-mail: danielle@ifes.edu.br.

Maria Regina Lopes Gomes. Professora titular do Curso de Pedagogia e do Mestrado em Segurança Pública da UVV PPGSPo. Coordenadora do Grupo de Pesquisa do CNPq "Currículos-formação em redes, cotidianos de escolas e direitos humanos" e membro do Grupo de Pesquisa "Currículos, cotidianos, culturas e redes de conhecimentos". Email: regilogo@ hotmail.com.

${ }^{1}$ Estética de escrita aprendida com Nilda Alves (2001) na tentativa de superar dicotomias ainda presentes e de, ao unir palavras, criar outros sentidos decorrentes de sua composição.
} 
Assim, nessas relações entre singularidades, os praticantes cotidianos (CERTEAU, 1994) criam modos de fazer e transitar que não se deixam capturar pelas tentativas de silenciamento e homogeneização impostas pelas políticas atuais de educação, apesar de algumas vezes, serem tomados por uma sensação de desânimo e "desesperança". Compondo com muitos outros profissionais da educação, ampliamos uma luta pela educação pública e de qualidade social (GARCIA; OLIVEIRA, 2016) que se tece em processos de troca entre esses diferentes praticantes ordinários que habitam os cotidianos desses múltiplos e variados contextos.

Desse modo, afirmamos os processos de constituição de coletivos como forma de luta política por um projeto de emancipação que se funda em "relações de autoridade partilhada" e pela "democratização dos saberes e das práticas sociais desenvolvidos em todos os espaços sociais" (OLIVEIRA, 2006, p. 145-147). Assim, vamos compreendendo com Santos e Oliveira que "a condição necessária e imprescindível para a democracia é a pluralidade”. Um tecer junto na diferença, como possíveis na construção desses coletivos que têm se afirmado como espaçostempos (ALVES, 2001) de tessitura de políticas inventivas que escapam e produzem outros modos de transitar nessa complexa rede de possíveis e antagonismos...

Oliveira (2006, p. 148) afirma que

[...] só a democracia entendida enquanto sistema social envolvendo todos os espaços de inserção constitutivos da formação de nossas 'redes de subjetividades', com o conjunto de saberes e de práticas reais que tecemos e que nos tecem, nos serve para pensar a emancipação social democratizante.

De modo contrário à ideia que considera a pluralidade de saberes e de práticas como maneira de constituição de um coletivo e de fortalecimento do espaço escolar público e democrático, enfrentamos, nesses nossos tempos, processos de imposição de verdades e regulação de modo especial por meio das políticas de currículo e de formações de professores -, que se colocam na contramão e tem produzido um desmonte das lutas historicamente produzidas pelos professores e professoras brasileiros por uma educação e uma escola onde caibam todos/as na diferença, e uma democracia que comporte a construção de novas relações social e novo direito (NEGRI, 2003).

Apoiadas nos estudos de Michel de Certeau (1994), entendemos que são nessas relações tecidas entre os praticantes da vida cotidiana que as políticas do cotidiano se inventam e, como artes de fazerpensar, tecem as micropolíticas desses cotidianos. Micropolíticas que, como modos sorrateiros e subterrâneos de praticar e conviver com as políticas impostas por um lugar de poder e de querer, inventam movimentos táticos que se insinuam, rompem e borram fronteiras, permitem 
vários percursos, tecem espaços, jogam, são oportunistas, aproveitam as ocasiões, apresentam continuidades e permanências... "São práticas cotidianas" (CERTEAU, 1994).

Nessa esteira de pensamento, tratamos nas pesquisas, que realizamos nas escolas públicas de ensino fundamental e médio, das políticas de currículo e de formações docentes a partir das teorias das práticas cotidianas (CERTEAU, 1994), compreendendo que nos cotidianos dessas escolas estão coexistindo as múltiplas dimensões e circunstâncias dessas políticas educacionais, em suas relações com as redes de saberes, fazeres, valores, poderes, afetos, significados e culturas docentes. Interessa-nos pensar as políticas de educação como processos que se constituem nos movimentos estratégicos e táticos (CERTEAU, 1994) desses praticantes que se instituem em meio aos entrelaçamentos dos múltiplos contextos de pertencimento desses sujeitos encarnados (NAJMANOVICH, 2001), habitantes das escolas. Interessa-nos ainda, pensar políticas de currículos e de formações considerando a complexidade (MORIN, 2007), os atravessamentos e a heterogeneidades dessas redes.

Desse modo, em meio às políticas de currículo e de formações oficiais que têm sido produzidas, desconsiderando as produções das escolas públicas e as lutas de seus professores - por meio de discursos totalizantes, preconceituosos e excludentes e que insistem em uma representação idealizada e padronizada de escolas - e, dessa maneira, invisibilizam as inscrições políticas e epistemológicas das práticas cotidianas, nossas pesquisas apostam nos movimentos sorrateiros e plurais que inventam cotidianamente escolas, os encontros das aulas e seus professores, de modos singulares e contínuos (GARCIA; OLIVEIRA, 2016), ou seja, nas micropolíticas cotidianas como forças e práticas que tem (re)existido a essas tentativas de desmonte.

Ao contrário do que alguns apontam, a história do cotidiano não é um terreno relegado aos hábitos e rotinas obscuras. As abordagens que incorporam a análise do cotidiano têm revelado todo um universo de tensões e movimento com uma potencialidade de confrontos, deixando entrever um mundo onde se multiplicam formas peculiares de resistência/luta, integração/diferenciação, permanência/transformação, onde a mudança não está excluída, mas sim vivenciada de diferentes formas. Assim, não se pode dizer que a história do cotidiano privilegie o estático, já que tem mostrado toda potencialidade do cotidiano como espaço de resistência ao processo de dominação (MATOS, 2002, p. 26).

Diferenças, acasos, incompletudes, imprevistos, burlas, artimanhas, contradições e belezas dessas práticas-políticas microbianas que inventam as escolas, desobedecem aos modelos e regulações e colocam em questão o modelo autoritário e mercadológico das atuais políticas de educação que insiste e acredita poder controlar, por exemplo, por meio da instituição de uma Base Nacional Comum Curricular (BNCC), da Medida Provisória do Ensino Médio, da proposição do 
"Projeto Escola Sem Partido" além de outras tentativas de silenciamentos e negações das produções docentes e de uniformização dos currículos escolares.

No entanto, é preciso considerar que os praticantes anônimos dos cotidianos, com seus jeitos e modos de fazer, muitas vezes sutis, também produzem nesses cotidianos práticas-políticas de controle e regulação. Nessa perspectiva, não tratamos as micropolíticas dos cotidianos e as intenções macropolíticas dos Governos em separado, mas como coexistentes em suas especificidades na gestão dos processos educacionais. Ou seja, isso não significa dizer que esses lugares, constituídos como um próprio, onde se distribuem elementos nas relações de coexistência (CERTEAU, 1994), não busquem produzir e compartilhar sentidos e significados comuns nos variados processos de constituição dessas políticas de currículo e de formações.

Outra questão que precisamos considerar é que não há muros que separam as escolas das tantas redes e contextos de produção dessas políticas. Alves (2010) nos ajuda nessa argumentação quando afirma que

[...] os muros das escolas são meras criações imaginárias, mas não indicam o que existe, no que se refere às relações entre as múltiplas e diversas redes educativas e as escolas: precisamos compreender que vivemos todos dentrofora das escolas e que o que é aprendidoensinado nas tantas redes de conhecimentos e significações em que vivemos entra em todos os contextos, porque está encarnado em nós (ALVES, 2010, p. 1197, grifo nosso).

Essa argumentação de Alves (2010), de que as redes se tecem dentrofora das escolas, faznos compreender ainda que os movimentos microbianos dos cotidianos também estão contaminados por essas variadas redes que afetam as relações tecidas entre os praticantes que habitam nesses cotidianos. Nesse sentido, essas diferentes micro-macro políticas educacionais que produzimos nessas redes também falam de nós mesmos: de nossas intenções, expectativas, desejos, valores, afetos e interesses, tramados nas múltiplas redes que pertencemos.

Nesse sentido, na contramão da ideia de que há uma única "verdade" a ser dita pelas políticas oficiais, nossa aposta está nas negociações e ampliação dessas redes como possibilidades de intercâmbios e compartilhamentos entre esses vários praticantes e protagonistas das políticas educacionais. Para nós, essas práticas de negociação afirmam outros sentidos para a educação, para as escolas e para os conhecimentos como maneiras de produzir outros modos de pensar currículos e formações e práticas mais democráticas nas escolas, assumindo as ideias de política e de conhecimento como modos de potencialização e expansão da vida.

Linhares (2000, p. 85) amplia nossa compreensão sobre os movimentos atuais quando afirma: 
Enquanto a política for projetada apenas nas decisões que ocorrem fora da escola, um espaço fundamental dentro dela estará sendo deixado vazio. Para que uma política potente educacional seja editada, precisamos da ação articulada das diferentes esferas sociais - em que a escola não pode se ausentar - trabalhadas com rigor para alimentar uma opinião pública que nos ajude a preservar e ampliar nossas conquistas educacionais, conferindo-lhe ressignificações que nos instrumentalizem para sonhar, mas também, para objetivar nossos avanços por um mundo mais solidário.

Assim, discutir as políticas de currículo enredadas às políticas de formação continuada em meio aos cotidianos é pensar na possibilidade de criação permanente e na impossibilidade dessas práticas serem determinadas, uniformizadas e aprisionadas em qualquer discurso generalizante que desconsidere seus movimentos, fluxos e singularidades dos sujeitos que praticam esses cotidianos.

Usamos essas argumentações iniciais para problematizarmos o momento atual e antidemocrático que vivemos na educação e nas escolas, com essas tentativas de padronização e silenciamentos de educadores e estudantes. Por outro lado, somos arrebatados pela força e beleza dos atos desses praticantes que lutam e (re)existem por uma educação e uma vida cotidiana mais democrática, solidária e amorosa.

Os movimentos das juventudes que ocuparam os espaçostempos (ALVES, 2001) escolares, as ruas e assembleias, afirmando o compromisso desses jovens com a educação pública diante das mudanças oficiais para o Ensino Médio, e o movimento provocado pela Associação Nacional de Pós-Graduação e Pesquisa em Educação (ANPEd) "Aqui já tem currículo", como um modo de visibilizar e potencializar os currículos praticados nas escolas a partir da tentativa de constituição da BNCC, por exemplo, evidenciaram desejos de produzir outros modos de viver as relações na/com a educação, efetivados pela luta, pela pretensão da multidão e pela potência de seus movimentos que inventam e constituem realidades democráticas - movimentos de construção da vida -, sendo "o político o cenário fundamental desse processo" (NEGRI, 2003).

Com essas aprendizagens pensamos que essas políticas dos cotidianos (CERTEAU, 1994) que, com suas "trajetórias, não determinadas, mas inesperadas, que alteram, corroem e mudam pouco a pouco os equilíbrios das constelações sociais" (1995, p. 250), funcionam como uma força contrária aos processos antidemocráticos que têm nos afetado e nos indignado nesse nosso "Estado democrático de direitos", com suas tentativas permanentes de invisibilização das multiplicidades e pluralidades. Desse modo, as políticas dos cotidianos potencializam as práticas curriculares e as formações docentes que se tecem e escapam e desobedecem as tentativas de padronizações e prescrições, com movimentos que se colocam na direção da criação de uma vida bonita e mais democrática. 
Assim sendo, em tempos de tentativas de centralização e homogeneização curricular e, por efeito, dos processos de formações e de avaliações, afirmamos ética e politicamente a urgência de desinviblização das práticas-políticas cotidianas que, como artes de fazer (CERTEAU, 1994) dos professores, afirmam docências e currículos que se tecem por um fazer com, encharcado pelas vozes, jeitos de fazer, burlas, artimanhas, estratégias e táticas negociadas com e entre esses praticantes das aulas - professores/as e estudantes. Por isso, faz-se necessário

Compreender como os sujeitos das práticas tecem seus conhecimentos de todos os tipos, buscando discutir, assim, o que poderíamos chamar o fazer curricular cotidiano e as lógicas de tecer conhecimentos nas redes cotidianas, as das escolas, de seus professores/professoras e de seus alunos/alunas, dentre tantas (ALVES, 2002, p. 17).

A nosso ver, são nas negociações, nos usos que esses praticantes cotidianos (CERTEAU, 1994) fazem das prescrições, num constante trançardestrançar dos conhecimentos enredados nos espaçostempos das escolas e, por efeito, da vida (FERRAÇO, 2006), que as micropolíticas dos cotidianos ganham, se tecem e se potencializam.

Nas pesquisas, com um transitar por diferentes escolas de ensino fundamental e médio, os encontros e conversas com professores/as e estudantes nas aulas, no pátio, nos corredores, laboratórios, entre outros espaços, deram-nos indícios de que as práticas-políticas oficiais e suas intenções nos modos de "fazer acontecer" continuam muito distantes de uma vida de escolas - dos desejos, expectativas, discórdias, sonhos, esperanças, desencontros, alegrias, conflitos, emoções, desafios e necessidades dos educadores/as e dos estudantes. Parece que passam longe dos enfrentamentos e das relações cotidianas que fazem surgir e alimentam as criações didáticas nas invenções das aulas.

Nas aulas que aconteciam nos laboratórios de informática, os professores "mais desarmados" se aproximavam, encostavam e tocavam seus alunos... Em algumas aulas, com as oficinas e brinquedos criados, parecia que o interesse pelo que acontecia era grande e que nada mais existia em sua volta... Parecia que ali também podiam assumir outros modos de ser professor, mais acolhedores, diferentes daquele que costumamos encontrar nas salas de aula "comuns": geralmente com o professor sentado em sua mesa, escrevendo no quadro, tentando falar, apesar do burburinho da sala, ou fazendo tudo isso quase ao mesmo tempo...

Esses e outros encontros com os cotidianos das escolas da pesquisa nos deram pistas desses enredamentos que tecem currículos e que, ao mesmo tempo, contam-nos de um jeito de fazer docente produzido nos diferentes contextos teórico-práticos (ALVES, 2010) de formações. 
Trazemos para esse trabalho/texto alguns fios dessas inúmeras práticas-políticas que, para nós, potencializam as esperanças nas escolas e na educação pública como direito de todos/as. Concordando com Garcia e Oliveira (2016, p. 196), trata-se de iniciativas emancipatórias e de um entendimento em que "ser professor transborda o discurso, pois se faz no fazer-saber e no presente e pressupõe, necessariamente, atividade intelectual, social, ética e política”.

\section{AS PESQUISAS COM OS COTIDIANOS COMO CAMINHOS DAS PESQUISAS}

A perspectiva epistemológico-metodológico-política defendida em nossas pesquisas, isto é, assumir a dimensão de complexidade das redes de conhecimentos tecidas nos cotidianos das escolas como potência para entendermos as relações produtoras de políticas de educação estabelecidas entre processos curriculares e de formações, estimula-nos a tentar problematizar os conhecimentos tecidos em cada ação cotidiana que produzem essas políticas, a partir das narrativas, usos e negociações que os praticantes fazem/têm feito dos textos oficiais.

Ao assumirmos em nossas pesquisas a dimensão de redes e os estudos e pesquisas com os cotidianos (FERRAÇO, 2003) tentando nos aproximar e compreender as tessituras dos currículos e formações nos cotidianos de escolas, em articulação com as demais redes de pertencimento dos praticantes das aulas - professores/as e estudantes -, levou-nos a entender que o transitar nas redes cotidianas exige de nós uma implicação com os processos vividos. Em muitos momentos, é preciso, para além do olhar, atuar com "sensibilidade" nessa superfície das relações, acreditando "na liberdade gazeteira das práticas" (CERTEAU, 1994) que se desviam sorrateiramente da ordem dogmática que as autoridades tentam manter.

Os encontros das aulas de Inglês pareciam produzir outros sentidos que transbordavam as formalidades da aprendizagem da língua... Os cochichos que faziam sorrisos brotar com a alegria das conquistas... Os encontros dos corpos iam mostrando infâncias que se transformavam, infâncias sempre se fazendo... Os movimentos de "indisciplina" na sala de aula "convencional" pareciam se dissolver... Em várias aulas, o que se sentia eram os efeitos das redes de afeto se manifestando com mais intensidade e também o prazer de estar realizando as atividades dos projetos que eram inventados... Trabalhos coletivos entre professores e brincadeiras e alunos, que em outro lugar, não eram vistos, ali eram possíveis, sem medo de que a autoridade docente fosse colocada em questão...

Acreditar e se deixar tocar por essas ações não conformistas como uma tentativa permanente de compreender o que aí está acontecendo e como vão sendo fabricados, nesses contextos cotidianos, os currículos e os processos de formações que rompem com as fronteiras da obediência 
e da uniformização. Nossa atenção está nos modos rizomáticos como as tantas forças sociais, em movimentos complexos e diversificados - com base nas necessidades em nossos contextos cotidianos de viver, com suas redes de conhecimentos e significações - vêm conseguindo articular e fazer surgir em lugares apropriados pelas decisões hegemônicas, trazendo possibilidades outras, aqui e ali, nas propostas que fazem nascer nesses espaçostempos (ALVES, 2001).

Assim, esse movimento de pesquisa nos move a trabalhar com as imagensnarrativas dos praticantes das escolas como pistas para compreensão da produção de políticas de currículo em suas relações com processos de formações. Seguindo as orientações de Ferraço (2015) ganham força os gestos, as conversas, os silêncios, as diferentes expressões de escrita e corpo, murais, fotografias, brincadeiras, jogos, rabiscos e demais pistas que "potencializam diferentes sentidos do que é vivido pelos sujeitos".

Um pátio, lugar da Educação Física na escola... E, também, das invenções de brincadeiras que, inicialmente, foram pensadas, na escola de ensino fundamental, em função do tumulto do recreio, mas que logo foram incorporadas como práticas-políticas desses momentos... Das variadas brincadeiras com a corda, surgiram as brincadeiras com barbantes que pareciam dançar nas mãos das crianças, tamanha a agilidade para fazer os trançados... os jogos de botão, os jogos de xadrez com tampinhas coloridas, os bate-papos, os corre-corre, os namoros, as paqueras, os jogos de vôlei na quadra e as regras inventadas...

Com o uso dessas imagensnarrativas, produzidas em nossas pesquisas pelos encontros com professores/as e estudantes e pelas tentativas de transitar nas redes tecidas nos diferentes espaçostempos da escola, buscamos trazer um pouco mais das invenções e discursos criados por esses sujeitos praticantes (CERTEAU, 1994) e que dão sentido às produções cotidianas, especialmente neste texto, as invenções dos currículos e das formações como micropolíticas dos cotidianos.

Torna-se importante considerar, ainda, que as pesquisas realizadas com os cotidianos, ao tomarem as narrativas como expressões das redes tecidas nas escolas, acabam envolvendo os próprios pesquisadores nessas redes. Como fala Alves $(2005$, p. 8), “[...] o pesquisador também não tem condição de fugir dessas redes, pois está nelas mergulhado, interpretando o que lê com tudo o que tem de encarnado, em si, teorias e conceitos, podendo deixar de ver algo que outro pesquisador veria".

Assim, as narrativas dos praticantes das escolas pesquisadas a que temos tido acesso têm se revelado muito mais como potencialidades de expressões das relações, dos fluxos, das redes 
estabelecidas com a nossa presença do que como identificação e/ou descrição de um fato acontecido tal e qual ocorreu, independente de nós. Isso significa dizer que, de alguma maneira, nós, na condição de pesquisadores/as com os cotidianos, estamos envolvidos/as na criação/tessitura das redes de narrativas daqueles momentos, não sendo possível negar que também somos responsáveis pelos conhecimentos que estamos produzindo nas escolas com as nossas pesquisas, o que nos leva a assumir, com Certeau (1994), a nossa condição de pesquisador praticante ${ }^{2}$, à medida que nos propomos realizar uma pesquisa narrando histórias tecidas por outras tantas histórias.

Nesses movimentos, apostando na força das práticas-políticas educacionais inventadas nas escolas, temos dialogado com Alves, Garcia, Certeau, Bhabha, Ferraço, Oliveira, Morin, entre outros, que buscam problematizar os modelos tradicionais de pesquisa criando possibilidades de registros e de discussões que buscam, sobretudo, aproximar-nos do vivido, levando-nos a considerar as múltiplas produções dos sujeitos que praticam os cotidianos.

\section{Encontros com as escolas e seus praticantes nas tessituras das micropolíticas dos cotidianos}

Nessas artes de fazer (CERTEAU, 1994) as aulas, os professores, na contramão das tentativas de desqualificação de suas produções e lutas, têm apontado à força dessas artes invisibilizadas, criadas no serviço da docência, que extrapolam as previsões e prescrições feitas pelas políticas oficiais de currículos e formações de professores/as. Do mesmo modo que os alunos marcam e alteram com seus usos (CERTEAU, 1994) os livros e as mochilas, os uniformes e cadernos, as carteiras, as paredes e portas dos banheiros, os praticantes da docência modificam os planejamentos, os livros didáticos, as propostas curriculares, os materiais e os projetos que chegam às escolas e também inventam, nas tessituras das redes de fazeressaberes (ALVES, 2001) que são produzidas e negociadas nos cotidianos das escolas, outros possíveis... Desse modo, protagonizam nessas tramas sua existência de autor... (CERTEAU, 1994).

Sem negar as políticas educacionais oficiais, buscamos esses processos microbianos, operatórios, o fraseado devido à bricolagem, à inventividade 'artesanal', à discursividade que combinam esses elementos, todos 'recebidos' e de cor indistinta (GIARD, 1994, p.15-16) que desafiam permanentemente esse instituído e colorem e encharcam de vida os cotidianos escolares.

Em um dos "bons encontros" produzidos durante a pesquisa numa escola de ensino médio, e apostando nas oportunidades e astúcias que o cotidiano em sua beleza e desobediência oferece para que as pessoas comuns possam inverter e subverter e reverter e burlar e tramar e inventar mesmo

\footnotetext{
${ }^{2}$ Para Certeau (1994, p. 151), "subindo, descendo e girando em torno dessas práticas, algo escapa sem cessar, que não pode ser dito nem 'ensinado', mas deve ser 'praticado' [...] É um dizer aquilo que o outro diz de sua arte, e não um dizer dessa arte".
} 
quando pretendem "obedecer ao prescrito" (SÜSSEKIND; PELLEGRINI; TAVEIRA, 2016), trazemos um pouco da conversa com o professor Raul quanto à retirada dos termos "gênero" e “orientação sexual” do Plano Estadual de Educação (PEE/ES). Na sala dos/as professores/as ele nos disse:

Me preocupa as pessoas que querem a retirada destes termos de toda e qualquer legislação. Isso para mim é extremamente preocupante. A partir do momento que você vem lutando para que diferenças sejam minimizadas na sociedade existe um grupo que parece que quer que essas diferenças fiquem cada vez piores. Eu me pergunto o que impacta na vida das pessoas a retirada destes termos na legislação?

Depois de uma pausa ele continua:

Aqui em Vitória nós tivemos uma briga terrível para que estes termos fossem mantidos e essa retirada não veio das igrejas dos protestantes, veio de uma reunião que o Bispo fez com $05 \mathrm{ou}$ 06 vereadores na véspera da votação. [...] qual é o problema de aparecer diversidade sexual? Ninguém vai ensinar ninguém a ser gay, se você pega uma escola como essa, você vê homossexuais aos montes.

Outra professora entra na conversa dizendo que

[...] se esses termos não estão mais no Plano Estadual de Educação não tem como cobrar do Estado ações efetivas para isso. [...] Talvez a questão de retirar, não haverá como cobrar do Estado. Ora, se não está no Plano Estadual de Educação não pode ser cobrado. Tudo não se baseia em cortar gastos?

Revertendo a lógica da obediência, esses professores sinalizam com suas narrativas indignações em relação à retirada dos termos "orientação sexual" e "gênero" do PEE ao mesmo tempo em que manifestam que essa atitude pode funcionar como uma estratégia para que não sejam cobradas as responsabilidades do Estado, ou seja, cobrar do Estado ações efetivas para garantias desses direitos. Em nossa opinião, apontam o imperativo de uma prática-política colonialista e desigual que nega o direito de todos/as à educação e à escola em suas diferenças.

Quando estivemos em uma escola municipal de ensino fundamental, em conversa com o professor João sobre os currículos e formações que tece com seus alunos nas aulas, ele falou de suas "invencionices"...

[...] Eu pego essa parte das diretrizes dos professores de educação física e vou adaptando [...]. Tem coisas que os alunos não gostam muito e aí mudo com eles. Além disso, acrescento sempre uma conversa sobre a organização da turma, o respeito pelo outro, sobre as faltas e os valores porque acho que isso está faltando muito hoje em dia.

Continuando as conversas, o professor que trabalha em dois municípios diferentes, contanos sobre as tessituras curriculares que vai produzindo: 
[...] Pego sugestões na Serra também. Sou de lá e sempre que dá, levo coisas daqui pra lá e trago também. Os alunos são parecidos e lá, fizemos umas coisas bem legais na formação que uso aqui. [...] Eu vou assim, procuro conversar muito com eles para envolvê-los e também estou sempre pela escola com eles...

Outros elementos das relações que tecem currículos e formações aparecem quando conversamos com a professora Leila.

Eu trato todos [os alunos] como meus filhos. Minhas aulas são assim, como você vê. Bem dinâmicas, com muito respeito às histórias de cada um. E o que eles mais gostam é quando eu corrijo o caderno e coloco um coração. Nossa, menino tem fila para ver quem ganha o primeiro coração no caderno e fazem até disputa para ver quem tem mais coração no final do mês (quando eu olho o caderno) [risos].

Ouvindo o que esses praticantes das aulas têm a dizer sobre suas artes de fazer cotidianas, começamos a entender que nos trançados da docência essas políticas de currículo e formações se multiplicam e se tecem, ao mesmo tempo e com todos. Ao contar seus fazeres microbianos, esses habitantes-artistas desdenhados pelos engenheiros-terapeutas da cidade (CERTEAU, 1996, p. 198) nos dão pistas de que quando nos propomos a pensar currículos e formações docentes, a partir do que é realizado (FERRAÇO, 2005) nos cotidianos escolares, esses processos vão se embolando nas teias das variadas relações que produzem.

Assim, nos cotidianos, as aulas e práticas desses professores se entrelaçam a tantas outras, mostrando seus jeitos singulares de fazer que, como inventores de trilhas nas selvas da racionalidade (CERTEAU, 1994), ampliam essas redes e traçam trajetórias indeterminadas nas escolas, contrariando o que se tem priorizado nas atuais políticas oficiais de educação e no Movimento Escola Sem Partido, por exemplo.

Por essa razão, em nossas pesquisas, apostamos e temos interesse por essas artes de fazer que se insinuam e se inventam (CERTEAU, 1994) nas tramas das redes de saberes, fazeres, afetos, conhecimentos, valores, poderes, sentidos, entre tantas outras, tecidas entre estudantes e professores/as que afirmam a própria vida, e que muitas vezes são negligenciadas por políticas colonialistas que inferiorizam certos grupos humanos, deslegitimando diferenças (SANTOS, 2016).

Assim, "transgredir uma normativa" ou alguma orientação das políticas oficiais diz das diferentes maneiras de fazer que tecem os cotidianos, criando outros limites, "desobedecendo" o que se pede e/ou o que está previsto. Isso nos provoca a pensar que quando um professor ultrapassa os "limites do esperado" traz uma marca da diferença, contrariando o que se acostumou a perceber como "legal" ou "normal"... Dessa maneira, ao pensar/sentir as intensidades do que é fabricado nas 
aulas por alguns professores, sentimos também que nos cotidianos há outras maneiras de fazer e de se relacionar que inventam as escolas, apesar dos descasos dos governos e governantes.

Os usos e táticas que criam cotidianamente as políticas microbianas de currículos e de formações estão inscritas nas redes de relações de forças entre o forte e o fraco e vão construindo um novo modelo de realidade social e de ações ali desenvolvidas (OLIVEIRA, 2001, p. 47).

Os encontros com os estudantes do ensino médio também foram potentes para compreendermos a força das docências e os sentidos que esses jovens produzem...

No bimestre que acabou nós também tivemos uma atividade bem legal... É muito difícil os professores do técnico e do médio fazerem alguma atividade junto... Acho que nunca teve! [...] Mas esse último bimestre teve e foi muito legal! Foi sobre a questão do lixo na escola que era assunto do técnico. Aí nós fizemos o recolhimento do lixo que é jogado em vários pontos do campus, fora das lixeiras, claro! E depois com a ajuda dos professores de Matemática e Estatística fizemos vários cálculos... Simulamos a quantidade de lixo que seria produzida em dias, meses e até no ano inteiro. Depois montamos gráficos e apresentamos uma proposta pra Direção da escola, pedindo a instalação de mais lixeiras, em vários pontos do campus e que foram localizados pelo mapa, através do Google. Ficou bem legal... (ESTUDANTE)

A conversa com a professora de Biologia também evidencia esses movimentos e intensidades que inventam os encontros das aulas...

Bom, a primeira atividade era uma Gincana! A turma foi dividida em quatro grupos, e cada grupo sorteava uma pergunta de um saquinho de pano, e tinha um minuto para respondê-la, sendo que o grupo todo poderia responder. [...] Se em um minuto ele não conseguisse achar a resposta eu abria a pergunta para o restante do grupo, que tinha mais um minuto para responder. Caso o grupo acertasse, ganhava dois pontos. E caso o grupo não acertasse, eles se lascavam, entendeu?! [Risos...] (PROFESSORA).

Compondo novas percepções e sensações, que rompem com o pensamento instituído, majoritário (DELEUZE; GUATTARI, 1996), fazendo abrir à vida novas possibilidades para além da reprodução e mesmice, essas artes de fazer (CERTEAU, 1994) as aulas também nos dão pistas das fragilidades dessas atuais políticas oficiais de educação diante da beleza e complexidade dessas práticas-políticas tecidas pelos docentes e estudantes que são vividas nas escolas. Em nossas idas às escolas, nos encontros com os professores durante os intervalos de aula, os fios das conversas eram puxados e se enredavam em uma produção de múltiplos sentidos quando falávamos da escola e das produções de seus praticantes...

Conversas com professoras do ensino fundamental tecem fios que, para nós, falam dessas diferenças e tensões que estão presentes nas redes tecidas entre os professores que atuam em uma mesma escola, com diferentes modos de pensarfazer, apostas políticas e desejos... 
- Esses alunos são uns demônios. Não sei pra que vem a escola. Também, né, precisam garantir o rango do almoço... (PROFESSORA)

- Minha turma melhorou muito. Hoje os alunos estão tirando boas notas e vejo que o trabalho tem sido recompensado com a aprendizagem dos alunos. Mas, temos muito que trabalhar. (PROFESSORA)

- Precisamos somar forças. Sempre compartilho com as minhas colegas professoras. Temos um clima muito bom para trabalhar no vespertino. Sinto falta de um clima de parceria no matutino e isso interfere em nossas atitudes pedagógicas. (PROFESSORA)

- Eu acho que a escola é isso. É falar de vida, de história de vida! (PROFESSORA)

Em meio ao pessimismo de algumas histórias compartilhadas entre docentes, encontramos outras que indicam uma docência que se inventa e que escapa de crenças e práticas de diminuição das crianças das escolas públicas.

Assim, em meio às experiências, às divergências, às crenças, aos valores e às táticas $e$ estratégias dos vários sujeitos dentro do lugar próprio (CERTEAU, 1994), os movimentos de produção curricular, de formação, de avaliação e dos sentidos de escolas vão se constituindo nas práticas de Leila, João, estudantes do ensino médio e do ensino fundamental, entre tantos outros docentes e estudantes...

Nossas pesquisas se encaminham para uma compreensão de que as políticas cotidianas de educação se constituem nas articulações, nos enredamentos e nas interpenetrações que se dão entre as políticas locais-globais, macro-micro, entendendo que todos esses processos se tramam a partir das experiências diferenciadas dos sujeitos que praticam os cotidianos, em suas relações de saber e poder, nas tensões, contradições e lutas desses praticantes. Processos que mostram a força do político nos estudos dos cotidianos, que evidenciam uma politização do cotidiano (CERTEAU, 1995).

São currículos e formações criadostecidos como micropolíticas dos cotidianos, que interligam as histórias dessas pessoas aos seus contextos de vida e à infinidade de experiências que os constituem. São ainda práticas que, para Alves (2002), devem "fazer emergir as tantas redes trançadas cotidianamente" (p. 57) nas escolas e que, em muitas ocasiões, não são consideradas, mesmo "sabendo" que esses praticantes chegam às escolas prenhes dessas redes.

Desse modo, compreendemos que são os sujeitos individuaiscoletivos (FERRAÇO, 2004) que imprimem suas marcas e articulam contextos religiosos, familiares, culturais, sociais e políticos, realizando suas práticas na efemeridade dos cotidianos. E, nesses momentos em que praticam as diferentes redes de saberesfazeres nas escolas, aparecem como sujeitos cotidianos que 
inventam currículos (FERRAÇO, 2004) e processos de formações. Por isto, para nós, pensar currículos e formações de professores/as só faz sentido se consideradas as redes de saberes, fazeres, poderes, valores, sentidos e significados que se trançam nos múltiplos cotidianos que pertencemos.

Problematizar certos discursos que naturalizam a negação e a desqualificação da escola pública parecendo desconhecê-la como espaçotempo de resistências, de lutas e de produção de formas múltiplas de sobrevivência, de alternativas escolares/pedagógicas/políticas e, ainda, como fruto de diferentes práticas de sujeitos históricos, sociais, culturais e políticos que não renunciam à dignidade da emancipação humana (LINHARES; NUNES, 2000) torna-se urgente. Sem contar que esses discursos de negação da escola pública procede a um verdadeiro "assassinato cultural", à medida que silencia e emudece os sujeitos que acabam por ocupar lugares subalternizados, “definidos por processos globalizadores, que vão sendo operados à nossa revelia" (LINHARES, 1999).

\section{REFERÊNCIAS}

ALVES, Nilda. Artefatos tecnológicos relacionados à imagem e ao som na expressão da cultura de afro-brasileiros e seu "uso" em processos curriculares de formação de professoras na Educação Superior: o caso do curso de Pedagogia da UERJ/Campus Maracanã. Projeto incorporado ao PROCIÊNCIA, agosto de 2005.

. (Org.). Criar currículo no cotidiano. São Paulo: Cortez, 2002.

Decifrando o pergaminho. In: OLIVEIRA, I. B.; ALVES, N. (Orgs.). Pesquisa no/do cotidiano das escolas. RJ: DP\&A, 2001.

. Redes educativas 'dentrofora' das escolas exemplificadas pela formação de professores. In: DALBEN, Â.; DINIZ, J.; LEAL, L.; SANTOS, L. (orgs.). Convergências e tensões no campo da formação e do trabalho docente. BH: Autêntica, 2010.

AZEVEDO, Joanir Gomes. Fazer com paixão sem perder a razão: retalhos de uma experiência em escola pública de tempo integral. 2001. Tese (Doutorado em Educação). Universidade Federal Fluminense. Niterói/RJ, 2001.

CERTEAU, Michel de. A cultura no plural. Tradução de Enid Abreu Dobránszky. 2 ed. São Paulo: Papirus, 1995.

. A invenção do cotidiano: 1: artes de fazer. RJ: Vozes, 1994.

. A invenção do cotidiano: 2. morar, cozinhar. RJ: Vozes, 1996.

DELEUZE, Giles; GUATTARI, Felix. Mil Platôs: capitalismo e esquizofrenia. Rio de Janeiro: Editora 34, 1996. vol. 3. FERRAÇO, Carlos E. Currículo, formação continuada de professores e cotidiano escolar: fragmentos de complexidade das redes vividas. In: FERRAÇO, C. E. (Org.). Cotidiano escolar, formação de professores (as) e currículo. São Paulo: Cortez, 2005.

Educação-clichê e a necessidade de rasgar sombrinhas... Ou sobre violências cotidianas e a necessidade de furar os clichês. In: GARCIA, R. L.; ESTEBAN, M. T.; SERPA, A. (Orgs.). Saberes cotidianos em diálogo. RJ: De Petrus; FAPERJ, 2015.

. Eu, caçador de mim. In: GARCIA, R. L. Método: pesquisa com o cotidiano. Rio de Janeiro: DP\&A, 2003.

. Os sujeitos das escolas e a complexidade de seus saberesfazeres: fragmentos das redes tecidas em pesquisas com o cotidiano. In: GARCIA, R.L.; ZACCUR, E. (Orgs.). Cotidiano e diferentes saberes. Rio de Janeiro: DP\&A, 2006.

Os sujeitos praticantes dos cotidianos das escolas e a invenção dos currículos. In: MOREIRA, A.F.B.; PACHECO, J.A.; GARCIA, R.L. (Orgs.). Currículo: pensar, sentir e diferir. Rio de Janeiro: DP\&A, 2004. 
GARCIA, Alexandra; OLIVEIRA, Inês B. Encontros e narrativas como formação: presenças e sentidos da justiça cognitiva nas escolas. In: OLIVEIRA, I.B.; SÜSSEKIND, Maria L. (Orgs.). Formação docente e justiça cognitiva: pesquisas, práticas e possibilidades. Petrópolis:: DP et Alii, 2016.

GIARD, Luce. História de uma pesquisa. In: CERTEAU, Michel de. A invenção do cotidiano: 1 . Artes de fazer. Petrópolis, RJ: Vozes, 1994.

GOMES. Maria R. Lopes. As múltiplas práticas-políticas de currículoformação tecidas com os cotidianos como possibilidades de potencialização da vida e dos sentidos das escolas. 2011.293 f. Tese (doutorado em Educação) Programa de Pós-Graduação em Educação. Universidade Federal do Espírito Santo, Vitória, 2011.

LINHARES, Célia Frazão. Escola Balaia: um convite ao debate para reinvenção de Caxias. Caxias/MA: Caburé, 1999.

; NUNES, Clarice. Trajetórias de magistério: memórias e lutas pela reinvenção da escola pública. Rio de Janeiro: Quartet, 2000.

MATOS, Maria Izilda S. Cotidiano e cultura: história, cidade e trabalho. Bauru, São Paulo: EDUSC, 2002.

MORIN, Edgar. Introdução ao pensamento complexo. Porto Alegre: Sulina, 2007.

NAJMANOVICH, Denise. O sujeito encarnado: questões para pesquisa no/do cotidiano. Rio de Janeiro: DP\&A, 2001.

NEGRI, Antonio. Cinco lições sobre império. Rio de Janeiro: DP\&A, 2003.

OLIVEIRA, Inês B. Boaventura e a educação. Belo Horizonte: Autêntica, 2006.

OLIVEIRA, Inês B. Certeau e as artes de fazer: as noções de uso, tática e trajetória na pesquisa em educação. In: OLIVEIRA, I. B. de; ALVES, N. (Orgs.). Pesquisa no/do cotidiano das escolas. Rio de Janeiro: DP\&A, 2001.

SANTOS, Boaventura S. A Crítica da Razão Indolente: Contra o desperdício da experiência. Porto: Afrontamento, 2000 .

A difícil democracia: reinventar as esquerdas. São Paulo: Boitempo, 2016.

SÜSSEKIND, Maria L.; PELLEGRINI, Raphael; TAVEIRA, Clara. Pesquisas, práticas e justiça cognitiva na formação de professorxs. In: OLIVEIRA, I.B.; SÜSSEKIND, Maria L. (Orgs.). Formação docente e justiça cognitiva: pesquisas, práticas e possibilidades. Petrópolis: DP et Alii, 2016. 


\section{RESUMO}

A escrita deste artigo objetiva problematizar os mecanismos de controle e regulação das atuais políticas educacionais que têm desconsiderado o que é produzido nos cotidianos escolares, afirmando a luta por uma educação pública e de qualidade social. Metodologicamente, usa os estudos e pesquisas com os cotidianos e, nos encontros com os praticantes, produz pistas e indícios de que são nas negociações e composições entre os diferentes saberes e práticas que as micropolíticas cotidianas se inventam e produzem movimentos de (re)existência à imposição de verdades e tentativas de homogeneização das políticas de currículo e de formações docentes. Considera ainda essas micropolíticas como possibilidades de construção do exercício de democracias nos cotidianos das escolas.

Palavras-chave: Currículos. Formações docentes. Micropolíticas.

\section{MICROPOLICIES, CURRICULUMS AND TRAINING IN SCHOOL INVENTIONS}

\section{ABSTRACT}

The writing of this article aims to problematize the mechanisms of control and regulation of current educational policies that have disregarded what is produced in school daily life, affirming the struggle for a public education and social quality. Methodologically, it uses studies and researches within daily life and, in meetings with practitioners, produces clues and indications that in the negotiations and compositions between the different knowledges and practices that daily micropolicies are invented and produce movements of (re)existence to imposition of truths and attempts to homogenize curriculum policies and teacher training. It also considers these micropolicies as possibilities of building the exercise of democracies in the daily life of schools.

Keywords: Curriculums. Teacher training. Micropolicies.

\section{MICROPOLÍTICAS, CURRICULOS Y FORMACIONES EN LAS INVENCIONES DE LAS ESCUELAS RESUMEN}

La escritura de este artículo objetiva problematizar los mecanismos de control y regulación de las actuales políticas educativas que han desconsiderado lo que se produce en los cotidianos escolares, afirmando la lucha por una educación pública y de calidad social. Metodológicamente, utiliza los estudios e investigaciones con los cotidianos y, en los encuentros con los practicantes, produce pistas e indicios de que son en las negociaciones y composiciones entre los diferentes saberes y prácticas que las micropolíticas cotidianas se inventan y producen movimientos de (re) existencia a la imposición de verdades e intentos de homogeneización de las políticas de currículo y de formaciones docentes. También considera estas micropolíticas como posibilidades de construcción del ejercicio de democracias en los cotidianos de las escuelas.

Palabras-clave: Currículos. Formación docente. Micropolíticas. 